\title{
Functional modelling for the automated control system of a threaded joints, such as threaded plug gauges
}

\author{
Mihail Shutikov ${ }^{1, *}$, Jurij Solomencev ${ }^{1}$, Alexandr Feofanov ${ }^{1}$ and Tat'jana Grishina ${ }^{1}$ \\ ${ }^{1}$ Moscow State University of «STANKIN», 127055, 1, Vadkovsky per., Moscow, Russian Federation
}

\begin{abstract}
The article presents a methodology for modelling the control of a threaded plug gauge. There had been examined works of scientists who had studied the aspects of the average thread diameter control and studied the problems of providing and improving the quality of threaded joints. At a modern machinebuilding enterprise, threaded gauges are important in controlling threaded joints of parts. There had been built a functional model of the caliber life-cycle. The article shows possible applications of threaded gauges and examines the method of automating the average thread diameter control on a universal three-axis measuring video microscope. The application of this method is expedient in the conditions of modern production, since that usage reduces time expenses and requirements for the operators' qualification, as well as increases the reliability of the results of the average thread diameter control.
\end{abstract}

At the present stage, improving the quality of machines and mechanisms is one of the priorities in the engineering industry, along with providing a high technical level. The development of science and technology, changing needs of the society are caused by the necessity of creation of the equipment, increase productivity and facilitate the term [1, P. 448; 2, P. 5].

The solution of these problems determines the profitability and increases the safety of operation of machines and mechanisms. One of the most important aspects of the modern economy in the engineering industry is the reduction of material and time expenses for new products [3, P. 114; 4, P. 54].

This problem can be solved, including with the use of special measuring tools and equipment.

While engineering industries have particular difficulty controlling operations associated with the measurement of threaded surfaces, since for a reliable operation of the product necessary to ensure the quality of threaded connections. Threaded connections have extremely wide application and represent approximately $20 \%$ of the total number of compounds in modern products, and in some cases, their share reaches $70 \%$. [5, P. 3].

However, due to the complexity of integrated control (which is especially important for internal threads) for both mass and small batch and individual production used control gauges, so you need to keep quality caliber at a level consistent with its functional purpose.

Integrated control of the thread parameters are mostly done by thread gauges which have to be maintained very precisely [6, P. 11].
Thus, it seems topical application of more effective techniques affecting factors reduce the time it takes to control the mean diameter of thread gauges and do not require highly skilled personnel.

The gauge is a control tool, reproducing the geometrical parameters of the elements of the product, determined by the given marginal linear or angular dimensions, and in contact with the element of the product on surfaces, lines or points (GOST 27284-87) [7, P. 3].

In the mass manufacture of products with threaded connections with the same size, are widely used tools of a rigid structure, such as a threaded plug gauges. Questions for the control of the mean diameter of the thread reflected in the works of domestic scientists: Z. G. Smilyanskogo, A. G. Skhirtladze, Y. M. Radkevich, V. I., Berkova, etc., as well as scientists and specialists of leading scientific and educational centers of the country. In recent years, much attention is paid to research of problems of ensuring and improving the quality of threaded connections on the basis of technological support and improve the quality of the working surfaces of the threads and their operational properties. In the solution of these problems is the great contribution made by such scientists as: A. N. Feofanov, A. V. Rybakov, A. N. Prokofiev, A. G. Suslov, A. V. Handozhko, etc.

However, the issues related to the improvement of thread control methods using automated computerized systems, allow to increase the reliability and effectiveness of the results of monitoring have not been sufficiently developed in the scientific and technical literature up to the present.

\footnotetext{
* Corresponding author: mi.shutikov93@yandex.ru
} 


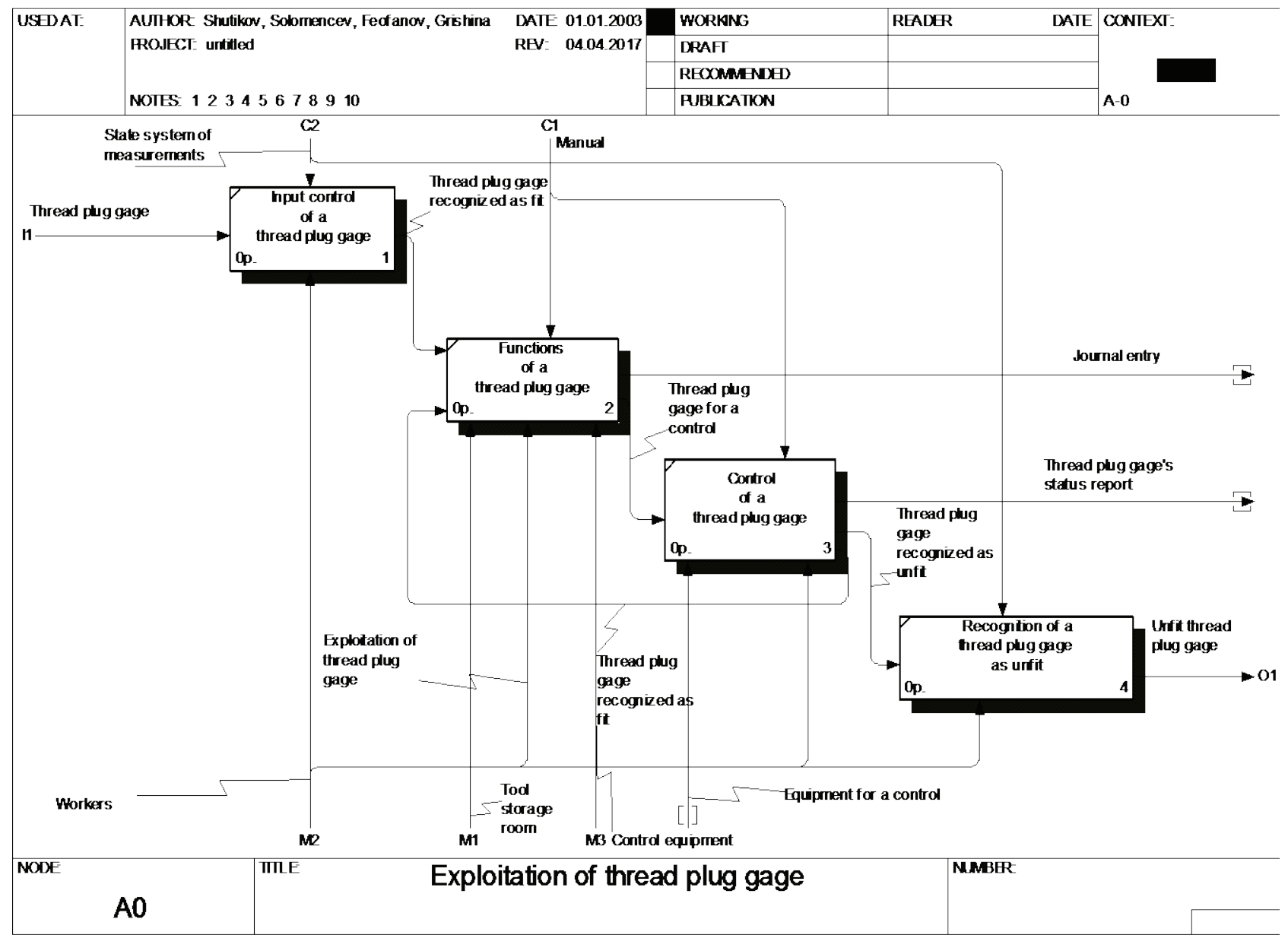

Fig. 1. Decomposition of the SADT-diagram of the exploitation's process of the threaded plug gages.

Assurance of the high quality of threaded calibers is a continuous process of high-quality production and controlling its quality. As follows from the diagrams SADT IDEF0 model (shown in Fig. 1) and its IDEF3 (Fig. 2), the operation of the gauges pass through certain stages of control.

We would like to note that in modern industries the need for their in-depth analysis and improvement is acute manifested. This is especially actual for integrated and automated enterprises. Under such conditions it is reasonable to use methods permitted to investigate the structure, characteristics and parameters of both the various production systems as a whole and their elements. The methodology of functional modeling could be accepted as one of such approaches.

The methodology of structural analysis is SADT (Structured Analysis and Design Technique) is a set of methods, rules and procedures for the construction of functional model of object of any subject area. This methodology is intended to reflect the functional structure of the object or process, that is, they produced the actions and relationships between these actions. In addition, it can be used to analyze the functions performed by the system, and to specify mechanisms through which they operate. And the application of this methodology to construct structural models in CAD could be very actual [5].

IDEF0 is used to create a functional model which is a structured image of the production system features and environment, or information and objects link those features [8, P. 62]. The IDEF0 model, or any model combination allows to formulate the "architecture" of the simulated system environment.

IDEF is a methodology, content architecture directly IDEF-diagrams, and performance improvement target.

As the decomposition of the IDEF0 model SADTdiagram shows one of the thread plug gauges life-cycle stages is the control its parameters. There are several methods to control the angle diameter in modern engineering, such as: two and three wires methods, projection one and the axial section method.

But all known methods in modern conditions do not provide the necessary economy of time resources and make strong requirements on skilled staff. It is necessary to improve the existing methods and enter the new ones. The management of the enterprise and the direct executors of the individual operations of the technological process in the field should be interested in improving the quality all the time [9, P. 285].

In this regard it is considered appropriate to develop a new method of monitoring the average diameter of thread plug gauges, which would be consistent with the requirements of mass production on the one hand, and also minimized the influence of human factor on the other side. This method is the measurement of average diameter of thread plug gauges on a universal three-axis video-microscope. Measuring microscope is designed for noncontact measurement of linear and angular 


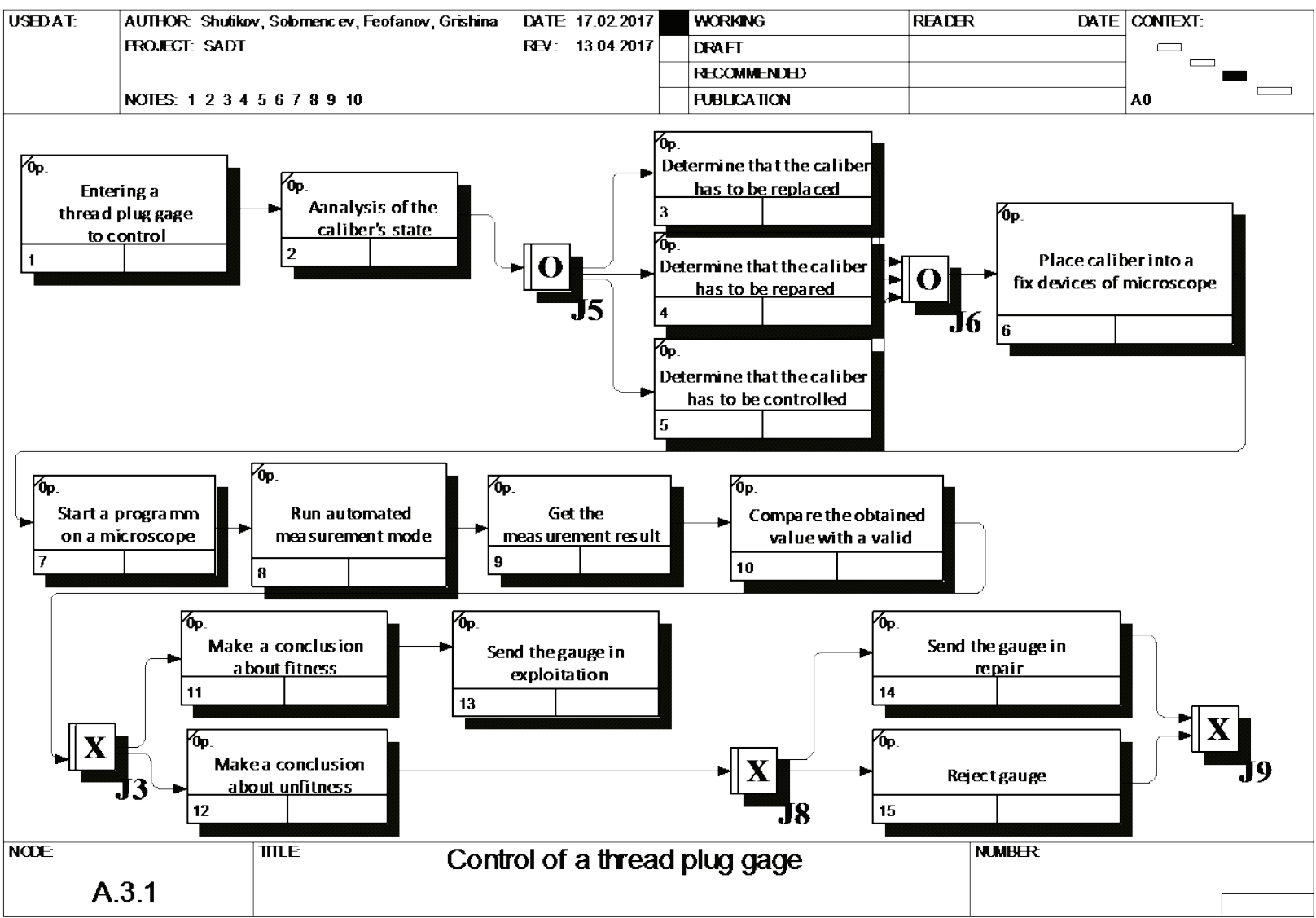

Fig.2. IDEF3 model of the threaded gauge-plug control.

dimensions of flat-surfaced parts, rotary bodies, threads and other precision instrumentation details.

The software "Saphir" had been used for the convenience work with microscope to automate the measurement method for the average diameter of thread plug gauges. To measure in auto mode, it's necessary first to measure the thread plug gauges in manual mode (the training mode), after the program store operations sequences and save them as file on PC that permits to measure thread plug gauges with the same data (diameter and leads) in auto mode. Figure 4 shows the process model for thread plug gauges monitoring using the IDEF3 diagram.

The introduction of the automated control method is justified in the modern realities of machine-building production, since process automation involves the acquisition of information flow for the collection and processing of data. As a result of the information statistics obtained, not only the time parameters are determined, but bottlenecks are also identified, in order to establish additional control or eliminate the process violation. And the method significantly reduces time resources for monitoring and the requirements for the personnel classification.

\section{References}

1. A. Feofanov, A. Skhirtladze, The organization and execution of works on maintenance of industrial machinery: textbook for the stud. of secondary vocational schools (Publishing center "Academy", Moscow, Russia, 2017)
2. A. Feofanov, M. Turapin, Automated systems of identification and analysis of supply risks to improve the efficiency of engineering production (Monography, 2016)

3. A. Feofanov, N. Sobrina, T. Grishina. The basic methodology of substantiation of the technological characteristics of the product, Vestnik MSTU "Stankin", №4 (2015)

4. A. Feofanov, V. Korneeva, N. Negrimovskaja, Calculation of the optimal number of experts and the amount of data to be detected based on the results of the preliminary survey, Welding international, №9 (2012)

5. A.Grigoriev, E-lectures. URL: http://masters.donntu.org/2010/fknt/bolotova/librar y/tez7.htm (2010).

6. A. Prokofiev, Technological support and improvement the quality of screwed joints: dis. ... of PhD in Engineering: 05.02.08: defense of the thesis 01.07.08 (Bryansk: Bryansk state technical University, 392 p., 2008)

7. GOST 27284-87. Gauges. Terms and definitions. state standard of the Russian Federation. Introduced 1988-01-01. 6 p. (2003)

8. RD IDEF $0-2000$. Methodology of functional modeling IDEF0. Guidance document. Edition official. p. 62 (2000)

9. R. Bouncers, A. Feofanov, V. Korneeva, E. Nakhapetyan, Qualimetry in mechanical engineering: the textbook, p. 285 (2009) 